\title{
TERCENTENARY CELEBRATIONS OF THE ROYAL SOCIETY
}

$\mathrm{T}$ HE programme of events which are to comprise the tercentenary celebrations of the Royal Society, due to take place during July 18-26, indicates that not only is the historical importance of the event to be appropriately marked but also that those who are to take part will have a good opportunity to become acquainted with active research work now being carried out in Great Britain.

Formal participation in the full programme will be limited to Fellows and Foreign Members of the Society and to those already invited to represent at the celebrations national academies of science, selected universities throughout the world, and appropriate international scientific organizations. The majority of the Foreign Members of the Society have already notified their intention of being present, and other distinguished men of science are among those who are coming from some fifty different countries. The British Commonwealth will be particularly well represented by large numbers, many of whom are Fellows of the Royal Society. The presence in London of so many leading scientists promises to make the occasion an outstanding scientific event.

In addition to the formal participants and their accompanying relatives, for whom the full programme of events has been principally devised, there will be a number of events to which others will be invited, notably the formal opening ceremony on the afternoon of July 19, which is to take place in the Royal Albert Hall. The ceremony will take the form of a few short speeches and the presentation of formal congratulatory messages by selected representatives attending the celebrations. For the occasion, Sir Arthur Bliss, Master of the Queen's Musick, is composing a "Salute to the Royal Society", and this will be played by Dr. G. Thalben-Ball on the organ together with the trumpeters and other musicians from the Royal Military School of Music, Kneller Hall. After an interval for tea the Society's president, Sir Cyril Hinshelwood, will deliver the tercentenary address.

In honour of the occasion the Universities of Oxford, Cambridge and London will have special honorary degree ceremonies, when degrees will be conferred on distinguished scientists attending the celebrations.

The Oxford and Cambridge ceremonies will take place on July 21 and July 25 , respectively, during visits to these Universities. While in Oxford, visits will be paid to the Colleges which will receive the Royal Society visitors at lunch. The conferment of honorary degrees will take place in the Sheldonian Theatre, the architect of which was Sir Christopher Wren, former president of the Royal Society, and this will be followed by a garden party at Wadham College, where meetings of importance in relation to the foundation of the Society took place. John Wilkins, Bishop of Chester and Warden of Wadham, was one of the Society's first secretaries. The visit to Cambridge will have a similar pattern, and in both Universities special exhibits relating to former Fellows of the Society are being specially arranged.
The University of London ceremony will take place in the Royal Festival Hall on July 22, where H.M. Queen Elizabeth the Queen Mother as Chancellor of the University will confer honorary degrees.

The following lectures will be delivered during the period of the celebrations in the Royal Institution, the Royal College of Surgeons, and the Beveridge Hall of the University of London: "Genetics and the Structure of Biology", by Prof. C. D. Darlington; "Trends in Aeronautical Science and Engineering", by Sir Arnold Hall ; "The Evolution of Nuclear Power Plant Design", by Sir Christopher Hinton; "The Physics and Chemistry of Nervous Conduction", by Prof. A. L. Hodgkin ; "Molecules in Crystals", by Dr. Dorothy Hodgkin; "The Investigation of the Universe by Radio Astronomy", by Prof. A. C. B. Lovell ; "The Problems of Transplantation", by Prof. P. B. Medawar; "The Study of Nuclear Interactions at Very Great Energies", by Prof. C. F. Powell ; "New Horizons in Organic Chemistry", by Sir Alexander Todd; "The Metamorphosis of Insects", by Prof. V. B. Wigglesworth.

The programme includes visits to university, government and industrial research laboratories which are or have been associated with the work of Fellows of the Society. In addition to visits to the Universities of Oxford and Cambridge, there are formally organized visits to the Imperial College of Science and Technology and University College in London, as well as informal visits privately arranged. The National Physical Laboratory, the Royal Botanic Gardens, Kew, the National Institutes for Medical Research, for Research in Nuclear Science and for Research in Dairying, as well as the Royal Aircraft Establishment, the Atomic Energy Research Establishment, the Geological Survey and Museum, and the Radio Research Station and Road Research Laboratory (Department of Scientific and Industrial Research) are among the national research institutions to be visited. The British Museum (Natural History) and the Science Museum are arranging special visits. The Associated Electrical Industries, Ltd., Research Laboratory at Aldermaston, the British Petroleum Research Centre, the General Electric Co. Research Laboratories, the Glaxo Research Laboratories, Imperial Chemical Industries, Ltd. (Plastics Division), the Wellcome Research Laboratories, and several research association laboratories provide a quota of industrial research visits.

Other events or visits recall the historical associations of the Society. The foundation of the Society in Gresham College near Guildhall in the City of London will be commemorated not only by two City receptions, one by the Lord Mayor in Guildhall and the other by the twelve great City Companies in the Mercers' Hall, but also on Sunday, July 24, by a sermon relating to Sir Christopher Wren, to be preached in St. Paul's Cathedral, of which he was the architect. One of the tours will re-visit the presentday Gresham College and also the other former homes of the Society in Crane Court off Fleet Street and Somerset House. Visits to Greenwich, where King Charles II instituted the Royal Greenwich Observa- 
tory, and the Chelsea Royal Hospital, built by Wren on a site once briefly owned by the Royal Society, are direct links with the Society's Royal founder. The Royal Mint, where Newton presided as master for many years, and Newton's birthplace at Woolsthorpe are also included in the places to be visited.

The Shell International Petroleum Company is making a special film for the occasion. This will be shown in the Royal Festival Hall on July 22, in a programme which will also include reference to the value of the film as a tool in scientific research. At the Society's tercentenary conversazione, to be held in Burlington House on July 23, a series of exhibits giving a presentation of current research work will be included in the programme of the evening, during which there will also be on display the congratulatory addresses received by the Society on the occasion of its three hundredth birthday. Some of the Society's treasures, such as the original reflecting telescope made by Sir Isaac Newton, the manuscript of New- ton's "Principia", the Society's Mace and the Charter" Book, both of which are gifts from the Society's Royal founder, will also be displayed on this occasion.

The celebrations will conclude with the tercentenary banquet on July 26, when the toast of "The Royal Society" will be proposed by the Prime Minister.

The issue of the first volumes of "The Correspondence of Isaac Newton", edited by Prof. H. W. Turnbull, happily coincides with the tercentenary year of the Society as a tribute to the Society's greatest Fellow. Two further historical works are being specially issued to mark the tercentenary occasion. These are a new brief history of the Society by Prof. E. N. da C. Andrade, and a volume of the Society's Notes and Records which is edited by Sir Harold Hartley. This special volume will give an account of the founder Fellows including Robert Boyle, Christopher Wren, Sir Robert Moray, Viscount Brouncker, Robert Hooke and others, as well as articles on the origins of the Society.

D. C. Martin

\title{
SOME CONSEQUENCES OF EXPANSION OF THE EARTH
}

\author{
By Prof. J. TUZO WILSON \\ Department of Geophysics, University of Toronto
}

\begin{abstract}
IN 1937 Dirac $^{1}$ suggested that the gravitational 1 constant $G$ is decreasing with time, proportionally to $t^{-1}$, where $t$ is the age of the universe. At that time $t$ was considered from astronomical evidence to be about $2 \times 10^{9}$ years, although age determinations indicated a greater age.

In two recent papers Dicke ${ }^{2,3}$ has discussed some of the consequences of this hypothesis using more recent estimates for $t$ of $6.5 \times 10^{8}$ and $12 \times 10^{9}$ years, respectively. Using the first figure he concludes that in the past $3.25 \times 10^{9}$ years the circumference of the Earth would have increased by about 4.5 per cent or 1,100 miles at an average rate of about $0.5 \mathrm{~mm}$. a year. $\mathrm{He}$ suggests that this expansion should still be recorded in cracks widely distributed over the ocean floors. He also finds no compelling evidence of a physical nature for or against Dirac's hypothesis and speculates whether "the history of the solar system as seen through the eyes of astronomers and geologists may enable fundamental conclusions to be drawn regarding physical interactions in the past". Egyed 4 is another who has long advocated an expansion of the Earth on geological grounds and has estimated a rate of increase in circumference of $3.8 \mathrm{~mm}$. a year.

It is proposed here to examine the geological and geophysical evidence briefly in the light of recent observations.
\end{abstract}

The information about the Earth has been chiefly contributed by stratigraphers, Precambrian geologists, students of physics of the Earth and oceanographers studying the sea-floor. Unfortunately, it has never been well integrated.

As a result of the International Geophysical Year, progress in oceanography has recently been very rapid. In 1956 Ewing and Heezen ${ }^{5}$ suggested that the mid-ocean ridges form a continuous, seismically active belt, extending through the Atlantic, Indian and South Pacific Oceans. They ${ }^{6}$ have since stated that a median rift valley already noticed by $\mathrm{Hill}^{7}$ is a characteristic feature, that it may be the locus of the earthquake foci, and that it (and perhaps the ridge in general) have intense magnetic anomalies "due to a subsurface body of high magnetic susceptibility". A branch of this rift has been traced to the Gulf of Aden $^{8}$ and thence to the rift valleys of Africa ${ }^{9}$, which have similar geophysical features.

Heezen ${ }^{10}$ suggests that the African rifts represent the start of another ocean and that existing ocean basins may have grown by the widening of such rifts under tension, "if, as the Earth's exterior expanded, the continental crust maintained a relatively constant area". Since the oceans occupy more than two-thirds of the Earth's surface, such an expansion would involve nearly doubling the Earth's radius during geological time. The impossibility of this has been pointed out by 'Teller ${ }^{11}$ and is appreciated by Heezen, who mentions that the postulate of an expanding Earth "may have other more serious objection of an astronomical nature".

If, on the other hand, one postulates that only the mid-ocean ridges and not the whole ocean basins have grown, the expansion would have been much less. Their width varies and is not accurately known, but Heezen's estimates seem to range from 400 to 800 miles. The length of the active ridges is 40,000 miles; but echo-soundings by U.S. Submarine Nautilus suggest a continuation of the mid-Atlantic ridge across the Arctic basin, parallel with the Lomonosov ridge ${ }^{12}$, and it has been suggested that some mid-Pacific ridges form part of the system, although seismically quiescent at present ${ }^{13,14}$. Including these gives a minimum length of the ridges of 60,000 miles and a minimum superficial expansion of about $2.4 \times 10^{7}$ square miles. This would require an increase in the Earth's circumference of about 6 per cent, and the formation of the ridges has probably required all geological time because there are no important abandoned ridges or any obvious way of 